\title{
RESERVAS EXTRATIVISTAS NA AMAZÔNIA: UMA VISÃO DOS ATORES POR MEIO DO DISCURSO DO SUJEITO COLETIVO
}

\author{
Neima Quele Almeida da Silva* \\ Carlos André da Silva Müller**
}

RESUMO: Este artigo teve como objetivo analisar como grupos de atores sociais distintos interpretam a institucionalização de Reservas Extrativistas (RESEX) apreciada do ponto de vista de uma política pública de conservação da biodiversidade. Foram considerados os extrativistas e os representantes de organizações que giram em torno das RESEX, diferenciadas em governamentais e não governamentais. Como referencial teórico, considerou-se a abordagem institucional e da sociologia organizacional. Metodologicamente, utilizou-se o Discurso do Sujeito Coletivo (DSC) como forma de compreender o discurso de ambos os grupos no que se refere à definição de extrativismo, desenvolvimento e sustentabilidade. Os resultados apontam para discursos bastante distintos, sendo que os extrativistas relacionam suas atividades como meio de sobrevivência, com pouca conotação ambiental. Por outro lado, os representantes das organizações governamentais demonstram ter um discurso politicamente correto, mas com pouca eficácia na gestão ou apoio às RESEX. As organizações não governamentais, por sua vez, encontram-se em uma posição intermediária, ora aproximando-se dos extrativistas ora das organizações públicas. Conclui-se que esse descompasso reflete negativamente na gestão destas Unidades de Conservação e que a sustentabilidade ainda não tem sido atingida nessas áreas, uma vez que a baixa renda tem feito extrativistas optarem por manejos florestais, cada vez mais frequentes.

PALAVRAS-CHAVE: Desenvolvimento; Extrativismo; Institucionalismo; Sociologia econômica; Sustentabilidade.

\section{EXTRACTIVIST RESERVES IN THE AMAZON: THE PERSPECTIVE OF PROTAGONISTS THROUGH THE DISCOURSE OF THE COLLECTIVE SUBJECT}

ABSTRACT: Current study analyzes how a team of social protagonists interpret the

Doutoranda em Desenvolvimento Regional (PGDRA/UNIR); Docente do Departamento de Economia da Universidade Federal de Rondônia (UNIR), Brasil.

** Doutor em Economia Aplicada pela UFV; Docente no Programa de Pós-graduação Profissional em Administração Pública da Universidade Federal de Rondônia (UNIR), Rondônia, Brasil;

E-mail: carlosandre@unir.br 
institutionalization of the Extractivist Reserves (RESEX) foregrounded on the public policy of the conservation of biodiversity. This implied government and non-government extractivists and organization representatives interested in RESEX. The institutional approach and organizational sociology were the theoretical referential and the Discourse of the Collective Subject was the method used for the understanding of the discourse of the two groups on extractivism, development and sustainability. Results reveal highly different discourses. Whereas extractivists relate their activities as survival means with low environmental connotation, the representatives of the government organizations had a politically correct discourse, with low efficiency in management or support for RESEX. On the other hand, the non-governmental organizations had an intermediate stance, sometimes tending towards the opinion of the extractivist and sometimes tending towards that of public organizations. Results show that this difference is a negative stance in the management of Conservation Units and that sustainability is not thoroughly effective in the area. In fact, low profits oblige extractivists to adopt forest management with great frequency.

KEY WORDS: Development; Extractivism; Institutionalism; Economic Sociology; Sustaibanility.

\section{INTRODUÇÃO}

A criação do Sistema Nacional de Unidades de Conservação (SNUC) é um esforço do governo brasileiro para gerenciamento do espaço territorial amazônico, com clara intenção de busca de meios institucionais de conservação da biodiversidade. Entre as Unidades de Conservações (UCs) definidas por lei (Lei n ${ }^{0} 9.985$, de 18 de julho de 2000), a Reserva Extrativista (RESEX) tem se mostrado bastante controversa na literatura que trata sobre o tema (ALLEGRETTI, 1997; HOMMA, 2008).

Historicamente, a institucionalização das RESEX foi um processo marcado por conflitos gerados pela oposição de interesses territoriais, onde populações locais remanescentes dos períodos econômicos da borracha tiveram que buscar a união com os povos indígenas para lutar contra grandes fazendeiros em defesa da floresta (ALLEGRETTI, 2002). Expoente daquele momento foi o seringueiro Chico Mendes, morto durante os conflitos, o qual simbolicamente representava um estilo de vida de relação sustentável entre a floresta e o ser humano.

Esta luta aos poucos se institucionalizou por meio da criação de aparato 
legal que reconhecesse as UCs, com sua população tradicional dentro desta área, em especial no território amazônico. Dos anos 2000 em diante, a forma de gestão adotada fundamenta-se na criação de Plano de Manejo dos recursos das RESEX, a partir da qual se definem as responsabilidades dos atores envolvidos (populações tradicionais, ICMBio, Associações, entre outros), e a forma de exploração da RESEX (Lei $\mathrm{n}^{0} 9.985$, de 18 de julho de 2000, art. 12-20). Inicia-se, a partir de então, uma nova fase, cujo desafio maior é a gestão compartilhada deste território.

No entanto, os problemas internos às RESEX permanecem, tais como extrações de madeira legitimados por parte do poder público ou extrações ilegais - sem plano de manejo - causadas por invasões e, ainda, ausência do Estado fiscalizador, bem como deficiência no gerenciamento da produção, organização, beneficiamento e transporte dos produtos (FACHINELLO; SIENA, 2009; VALIANTE, 2008; MOREIRA, 2010). Tais constatações evidenciam uma possível desestruturação social e econômica causada pela implementação das regras de utilização das RESEX e ineficiência em sua gestão, da qual deriva a presença de conflitos gerados por interesses de grupos tais como os madeireiros que, com seu avanço nas UCs, aumentam a área desmatada da floresta amazônica.

A presença de conflitos de interesses, lutas de poder, bem como o processo de institucionalização pelo qual passou a Amazônia brasileira, conduziu essa região para esta forma inovadora de gestão (conservação com presença humana), no entanto, ainda se necessitam análises que permitam o entendimento de como esse processo tem ocorrido na realidade dessas populações tradicionais.

O entendimento de como as regras são compreendidas pelos atores requer um arcabouço específico. Neste trabalho optou-se pela teoria institucional, a qual traz conceitos como mitos, cerimônias, campo organizacional e cognição como elementos explicativos das adesões e contraposições às mudanças em um determinando espaço de atuação na qual atores sociais interagem para definição das regras vigentes sejam elas formais ou informais (MEYER; ROWAN, 1977; POWELL; DIMAGGIO, 1991; TOLBERT; ZUCKER, 2010).

Entendeu-se, pois, as reservas extrativistas como campos organizacionais (DIMAGGIO; POWELL, 1983), nas quais há lutas de poder, onde a estabilização do campo está relacionada à perpetuação de regras e valores, que beneficiam os atores 
sociais dominantes em detrimento dos grupos dominados, tal como definido por Fligstein (2007).

Dessa forma, este artigo teve como objetivo analisar o discurso e interpretação dos atores envolvidos acerca de Reservas Extrativistas. Especificamente buscouse: (i) compreender o discurso dos atores sobre o conceito de extrativismo, desenvolvimento e sustentabilidade; (ii) comparar os discursos desses grupos de atores; e (iii) verificar como esses discursos se alinham à definição de Reserva Extrativista.

$\mathrm{O}$ trabalho discute primeiro a abordagem institucionalista e seus conceitos principais. Na sequência, apresentou-se histórico do processo de institucionalização das Reservas Extrativistas, bem como a visão acadêmica dos principais experts no assunto. Posteriormente, indicou-se os procedimentos metodológicos utilizados na pesquisa, para em seguida pelos resultados e discussões. Por fim, foram apresentadas as conclusões da pesquisa e considerações acerca das relações existentes no seio das RESEX e seu entorno.

\section{REVISÃO BIBLIOGRÁFICA}

\subsection{TEORIA INSTITUCIONAL E A SOCIOLOGIA ECONÔMICA}

A perspectiva institucionalista teve sua origem com a contraposição à teoria econômica clássica e neoclássica que colocavam o centro de sua análise no individualismo metodológico, caso que limitava a análise de aspectos sociais, culturais e ambientais, caracterizados por variáveis não econômicas. Fatores psicológicos e conflitos de poder, por exemplo, que extrapolam a noção de mercados não encontram consonância no mainstream econômico. No intuito de superar tais limitações, a escola histórica alemã busca a explicação dos determinantes dos fenômenos econômicos a partir de fatores psicológicos, conciliando a História com a Economia e a Sociologia, gerando algumas subteorias, as quais se destaca a formulação da teoria institucionalista pelos norte-americanos (MOURÃO, 2007).

O velho institucionalismo foi consolidado a partir dos trabalhos de Thorstein Bunde Veblen, John Rogers Commons e Wesley Clair Mitchell, os quais davam destaque para o estudo da estrutura, das regras e dos comportamentos de organiza- 
ções, que são moldadas pela visão das pessoas, o que altera ou fortalecendo o seu próprio ponto de vista, e gera os mercados através de um processo adaptativo ou de coerção institucional (CONCEIÇÃO, 2002). Em outras palavras, as instituições mudam e com estas mudanças pressionam o sistema gerando conflitos e crises (tensão entre ruptura e regularidade), levando a mudanças de atitudes e ações (CONCEIÇÃO, 2002).

A partir dos anos 70, o institucionalismo é reformulado tendo sua análise ampliada, adicionando o conceito de ambiente, arena ou campo organizacional, gerando diversas perspectivas institucionalistas tais como institucionalismo histórico, institucionalismo da escolha racional e o institucionalismo sociológico, sendo que deste último tem-se a análise organizacional.

O institucionalismo na sociologia organizacional inicia-se contrapondo ao ponto de vista weberiano, cujo entendimento fundamenta-se na organização de ação racionalizada, com foco na eficiência produtiva; ou seja, com objetivos a serem alcançados por meio de um sistema de regras e papéis pré-determinados. Porém, o paradigma weberiano foi questionado por estudos sociológicos que sugerem uma realidade socialmente construída (BERGER; LUCKMANN, 2011). Meyer e Rowan (1977) argumentam que a organização não é suficiente para explicar todos os fatores que determinam a instituição, havendo, segundo os autores, elementos ou estruturas imersas em um ambiente social gerando mitos, crenças e hábitos sociais que incorporados irão gerar novos elementos e, portanto, mudanças no ambiente institucional.

O campo organizacional pode, então, ser definido como área de vida institucional de diversos atores, no agregado, na qual o campo estruturado representa um ambiente de respostas organizacionais no sentido de representação na qual seu relacionamento se delimita (DIMAGGIO; POWELL, 1983).

Seis perspectivas teóricas de campo organizacional podem ser desenvolvidas buscando delimitar a amplitude conceitual de DiMaggio e Powell: (i) campo como a totalidade dos atores relevantes; (ii) campo como arena funcionalmente específica; (iii) campo como centro de diálogo e de discussão; (iv) campo como arena de poder e de conflito; (v) campo como esfera institucional de interesses em disputa; e (vi) campo como rede estruturada de relacionamentos (MACHADO-DA-SILVA; 
GUARIDO FILHO; ROSSONI, 2010). O campo seria, portanto, um ambiente onde se dá o processo de institucionalização, ou seja, onde os elementos são criados dando sequência ao surgimento de organizações que, futuramente, irão se consolidar ou gerar novas instituições.

Destaque deve ser feito para a conceituação feita por Fligstein (2007, p. 62), que identificou o campo como "situações nas quais grupos organizados de atores se reúnem e desenvolvem suas ações recíprocas face a face". O autor dá uma ênfase diferenciada ao afirmar que o campo é moldado ou induzido pela ação dos atores mais habilidosos socialmente, levando a cooperação de outros atores, e, por conseguinte, uma ação coletiva que irá construir e reproduzir ordens sociais locais, novos campos organizacionais. Tal perspectiva guarda relação com o campo como esfera institucional de interesses em disputa, sendo útil para a compreensão das relações sociais geradas por interesse, cooperação e, portanto, novas ordens sociais.

A Nova Sociologia Econômica, na qual Fligstein (2007) se filia, enfatiza que comportamento econômico do ser humano parte de uma imersão social, logo a escola tenta dialogar tanto com a Economia, quanto com a Sociologia Geral ou Organizacional (GRANOVETTER, 1985; SWEDBERG, 2004). As relações sociais podem, então, ser consideradas como variável-chave na compreensão do campo organizacional que passa a ser moldado pela ação coletiva dos atores que, induzidos a cooperar, proporcionam novas identidades e quadro cultural a esses campos (FLIGSTEIN, 2007).

A transformação no interior do campo, portanto, dá-se pela influência de atores-chave ou socialmente mais hábeis que utilizam sua percepção do conjunto de indivíduos de forma a proporcionar uma interpretação da situação, o que determina as ações que estão de acordo com interesses e as identidades existentes; isto possibilita atingir fins coletivos (FLIGSTEIN, 2007). Entretanto, Swedberg (2004) ressalta que a compreensão dos atores é subjetiva, uma vez que seus interesses podem ser diversos (materiais, emocionais, políticos ou econômicos), e influenciam o comportamento humano, porém, são sempre socialmente construídos concretizando-se por meio das relações sociais. Entretanto, devida atenção deve ser dada ao interesse na análise, uma vez que podem ser considerados do ponto de vista material, emocional, político, entre outros, porém, são sempre socialmente construídos concretizando-se 
por meio das relações sociais (SWEDBERG, 2004). Tolbert e Zucker (2010) destacam a ação de champions, conforme denominado por Dimaggio (1988), indivíduos com interesse na estrutura material e que atuam na busca de solução para problemas organizacionais, o que justificaria determinados arranjos na estrutura formal.

Sob esse prisma, as instituições seriam resultantes das ações dos indivíduos, que em busca de interesses, coletivos ou não, geram uma nova realidade coletiva, com a institucionalização de novas identidades.

\subsection{RESERVAS EXTRATIVISTAS}

Até meados do século XVII, a borracha era apenas mais um dos vários produtos da região amazônica, condição que se modificou a partir da Revolução Industrial em 1760, quando se instituiu o primeiro ciclo da borracha. A industrialização elevou consideravelmente a demanda por látex (matéria-prima da borracha), dada a necessidade de elementos flexíveis na produção industrial.

O látex era extraído manualmente, e suas árvores estavam distribuídas irregularmente no seio da floresta amazônica. Todavia, com o advento da produção plantada na Malásia, a produção extrativa brasileira entra em decadência. Com a Segunda Guerra Mundial (1939-1945), tem-se a invasão japonesa naquele país, o que tornou a atividade extrativista brasileira determinante para a produção de armas dos aliados Estados Unidos, Inglaterra e União Soviética. A importância foi tamanha que o presidente Getúlio Vargas convocou trabalhadores para a Amazônia os chamando de "soldados da borracha".

Em ambos os ciclos, houve uma grande migração da população nordestina para a região amazônica em condições assemelhadas a trabalhadores rurais, com vistas a atender a demanda exportadora do látex. Entretanto, muitos deles permaneceram na região mesmo com o declínio da produção, formando as populações tradicionais que ainda vivem na floresta (MACIEL, 2003). Conforme salienta Allegretti (2008), estes povos remanescentes são resultantes do abandono em antigos seringais. São seringueiros, extrativistas, ribeirinhos, pescadores, castanheiros, quebradeiras de coco babaçu - pobres e marginalizados que optaram por permanecer na floresta. 
A partir do governo militar, em 1964, implanta-se o plano de unificação nacional, com a construção de novas rodovias e avanço da migração. Na região amazônica foram traduzidos em novos empreendimentos, que contrapunham à lógica até então vigente (BECKER, 2001). No oeste amazônico, em especial em Rondônia, a partir de 1966, passa a ser realizado um planejamento efetivo na região com a implantação do Banco da Borracha, futuro Banco da Amazônia e a criação da Superintendência de Desenvolvimento da Amazônia (SUDAM), em substituição à extinta Superintendência do Plano de Valorização Econômica da Amazônia (SPVEA). Mas, no início dos anos 1980, foi lançado o Projeto de Desenvolvimento Integrado do Noroeste do Brasil (POLONOROESTE) com recursos do Governo Federal e Banco Mundial, e que visava absorver a população de outros Estados através do uso da terra da região (EMBRAPA, 2012), cujo resultado foi a implantação de um modelo de desenvolvimento baseado na grande empresa agropecuária (CAVALCANTI, 2002).

Dessa forma, desenhou-se um cenário de desvalorização da população local, que viu os antigos seringais transformados em pastos, o que precarizou suas condições de habitação, já afetadas pela desvalorização do produto (SIENA et al., 2011). Na região até então, os conflitos envolviam os seringueiros e índios, sendo os primeiros tidos como invasores em busca da seringueira para aumento de sua produção. Com o projeto militar, surgem novos conflitos, desta vez entre seringueiros e o agronegócio sob a lógica capitalista, desencadeando a ação de movimentos sociais em defesa da floresta.

Em 1975, por iniciativa da Confederação Nacional dos Trabalhadores em Agricultura (CONTAG), foram criados os primeiros Sindicatos de Trabalhadores Rurais (STR) que passam a intermediar os conflitos (ALLEGRETTI, 2008). Chico Mendes, um líder da época, articula-se junto às organizações e ao movimento ambiental internacional modificando a tônica do discurso, que além da disputa pela terra adquire a temática da conservação dos recursos naturais (MACIEL, 2003). Em 1988, Chico Mendes é assassinado.

Ainda, agregando-se a um novo segmento, antes opositor, os indígenas ampliam o movimento social, sendo identificados como "povos da floresta", passando à luta pela Reforma Agrária (ALLEGRETTI, 2002). Organizados, os Povos da Floresta, através de um movimento chamado "empates", impediam o desmatamento da floresta (ALLEGRETTI, 2008). 
Em 1985 é, então, realizado o $1^{\circ}$ Encontro Nacional dos Seringueiros, onde foi criado o Conselho Nacional dos Seringueiros (CNS) e formulada uma proposta que culminou na criação das Reservas Extrativistas (RESEX):

Áreas de extrativismo sustentável, de domínio público ou privado, desapropriadas para este fim, regularizadas através de concessões de direito real de uso do poder público a populações locais organizadas em associações ou cooperativas, tendo como principais objetivos a conservação do meio ambiente, a regularização da situação fundiária das populações locais, o desenvolvimento socialmente justo, ecologicamente sustentável e economicamente viável da região e a realização de pesquisas científicas voltadas à consecução dos objetivos anteriores (MOREIRA, 2010, p. 30).

Tal conceito foi utilizado como base para formulação da Lei $\mathrm{n}^{0} 9.985$, publicada em 18 de julho de 2000, que institucionaliza as Unidades de Conservação (SNUC), incluindo nestas as Reservas Extrativistas, conforme definição descrita no art. 18:

A Reserva Extrativista é uma área utilizada por populações extrativistas tradicionais, cuja subsistência baseia-se no extrativismo e, complementarmente, na agricultura de subsistência e na criação de animais de pequeno porte, e tem como objetivos básicos proteger os meios de vida e a cultura dessas populações, e assegurar o uso sustentável dos recursos naturais da unidade.

Em Rondônia, ainda em 1988, foi realizada a primeira aproximação do zoneamento socioeconômico ecológico (ZSEE), seguido do Plano Agropecuário e Florestal de Rondônia (PLANAFLORO), cuja meta assegurava a criação de unidades de conservação estaduais, a partir da qual a maioria das áreas protegidas do Estado foi criada, durante os anos de 1990 (SIENA; FACHINELLO; MAIA, 2010).

No entanto, a criação e institucionalização das RESEX não dirimiu totalmente os problemas existentes na região, visto que o aparato legal criado apresentava "fragilidade" e "instabilidade" (MOREIRA, 2010). Além disso, permanece a extração de madeira ilegal ou legitimados pelo poder público, ou pela ausência do Estado no interior das reservas e deficiência no gerenciamento da produção, organização, beneficiamento e transporte dos produtos (FACHINELLO; SIENA, 2009; VALIANTE, 2008; MOREIRA, 2010). 
Análise à luz da teoria institucionalista poderá, desta forma, permitir a compreensão das relações sociais e conflitos de poder existentes no interior das reservas extrativistas contrapondo-os com sua proposta de criação.

\section{MATERIAL E MÉTODOS}

A pesquisa foi realizada sob abordagem qualitativa e perspectiva descritivo -analítica, considerando a intenção de descrever e interpretar o fenômeno inerente às Reservas Extrativistas. Mais especificamente, pretendeu-se capturar a realidade no Estado de Rondônia sob o ponto de vista dos próprios atores. Como suporte, foram realizadas duas pesquisas: (a) pesquisa documental e (b) pesquisa de campo com base em dados da pesquisa "Busca da Sustentabilidade para os Produtos Não-Madeiráveis (PFNM) para o Estado de Rondônia" (Casadinho) (UNIR, 2011).

A população para coleta de dados foi composta por atores envolvidos com gestão das RESEX, distribuídos em três grandes grupos: a) Órgãos públicos relacionados (ICMBio, SEDAM, EMATER e algumas prefeituras); b) representantes das associações dos extrativistas; c) moradores e atravessadores de produtos da floresta, que foram coletados em idas sistemáticas a campo entre os anos de 2011 e 2013.

Devido à dificuldade de acesso em algumas localidades no interior da floresta, bem como a ausência de um estudo censitário que determine a população tradicional, a amostra desta pesquisa foi não probabilista e acidental (FORTIN, 1999). Percorreu-se os municípios de Costa Marques, Guarajá Mirim, Nova Mamoré, Porto Velho, Machadinho d'Oeste e Cujubim, onde estão localizadas todas as 26 RESEX existentes do Estado, com a finalidade de encontrar os atores sociais, seguindo esta sequência: a) informar-se junto aos órgãos responsáveis e entrevistá-los (ICMBio e SEDAM); b) fazer contato com as associações de moradores e entrevistar seus responsáveis; e c) adentrar às RESEX na medida da possibilidade para visitar extrativistas.

Apesar da característica de amostra acidental, cuja intencionalidade se dá conforme os entrevistados vão surgindo, foi possível coincidir a visita da equipe de pesquisa com reuniões de extrativistas. Sendo assim, totalizou-se 78 (setenta e 
oito) atores entrevistados, sendo 46 (quarenta e seis) extrativistas ou produtores; 17 (dezessete) representantes de organizações privadas; e 15 (quinze) de organizações públicas.

Por extrativistas, se compreendem os moradores das RESEX, cuja subsistência baseia-se na extração de produtos não madeireiros. Por organizações compreendem-se as organizações privadas tais como associações de moradores rurais, de produtores, de seringueiros, bem como públicas, tais como Secretaria de Desenvolvimento Ambiental (SEDAM), Associação de Assistência Técnica e Extensão Rural do Estado de Rondônia (EMATER), Instituto Chico Mendes de Conservação da Biodiversidade (ICMBio), Secretaria de Estado da Agricultura, Pecuária e Regularização Fundiária (SEAGRI).

Foi perguntado a estes atores, de forma aberta, três questões com vistas à compreensão do conceito de reservas extrativistas, conforme sua formulação inicial, a qual se relaciona com desenvolvimento sustentável, tal como segue:

1. Para você qual o significado de extrativismo?

2. Para você qual o significado de desenvolvimento?

3. Para você qual o significado de sustentável?

Para análise dos dados, optou-se pela utilização do Discurso do Sujeito Coletivo (DSC), que é uma proposta de organização e tabulação de dados qualitativos de natureza verbal, obtidos de depoimentos (LEFEVRE; LEFEVRE, 2006).

O DSC é uma técnica que pode ser utilizada como ferramenta de sistematização de experiências acumuladas (LEFEVRE; CRESTANA; CORNETTA, 2003). Fundamenta-se na teoria da Reprodução Social e seus fundamentos sociológicos (LEFEVRE; CRESTANA; CORNETTA, 2003).

Sua matéria-prima é o depoimento organizado em um ou mais discursossíntese escrito na primeira pessoa do singular, expressando dessa forma o discurso como se uma coletividade fosse o emissor, como se fosse um único discurso individual (LEFEVRE; CRESTANA; CORNETTA, 2003; LEFEVRE; LEFEVRE, 2006). De cada resposta (de uma entrevista) individual ou depoimento, tira-se as "expressões-chave", que são partes mais significativas da mensagem, revelando a essência do con- 
teúdo do discurso. Em seguida, destacam-se as ideias centrais que são uma síntese das expressões-chave, as quais poderão ser descritas sinteticamente por meio da ancoragem, que por fim levarão à representação de um "eu coletivo" no discurso do sujeito coletivo em si (LEFEVRE; CRESTANA; CORNETTA, 2003; LEFEVRE; LEFEVRE, 2006).

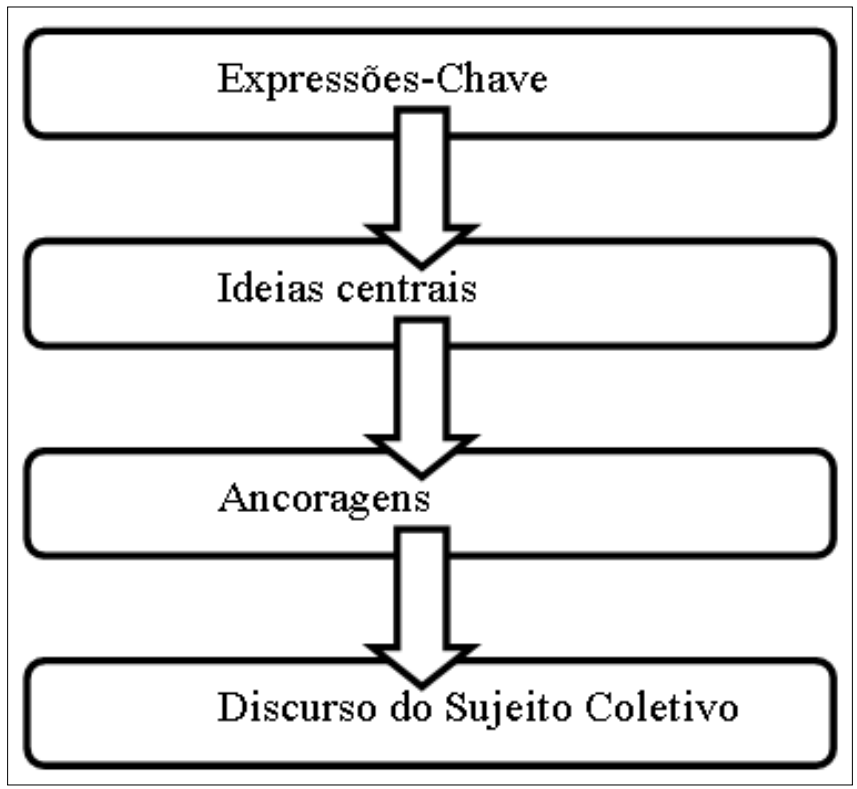

Figura 1. Etapas do DSC

Fonte: Elaborada pelos autores com base em Lefevre, Crestana e Cornetta (2003, p. 70).

Esta metodologia visa dar maior acuidade e validade à pesquisa, auxiliando encontrar o porquê ao invés de apenas identificar um problema. Sua aplicação tem demonstrado eficácia para o processamento e expressão das opiniões coletivas (LEFEVRE; LEFEVRE, 2006). Conforme destaque de Lefevre e Lefevre (2006), o DSC não deve ser confundido com uma representação social de uma coletividade, mas tão apenas como uma camada desta, podendo ser agregadas diversas outras camadas diretamente sobre a primeira.

A ideia de sujeito coletivo pode ser utilizada do ponto de vista da teoria institucionalista, cujo objeto, as relações sociais, são também vistas como um produto coletivizado das reações individuais tornadas comuns. Com esse intuito, o DSC foi 
considerado uma ferramenta fundamental para a compreensão do discurso oriundo dos atores que giram em torno da produção extrativa do Estado de Rondônia.

Dessa maneira, a própria forma de pensar entre os extrativistas é resultado do processo institucional, ocorrido no campo das reservas extrativistas. Assim, os depoimentos ou entrevistas foram tomados como ponto inicial para realização do DSC. Em seguida, destacaram-se as ideias centrais, que por efeito desta pesquisa, foram categorizadas a partir dos conceitos e entendimentos de experts relacionados aos temas em questão.

\section{RESULTADOS E DISCUSSÃO}

$\mathrm{O}$ art. $2^{\circ}$ da Lei $\mathrm{n}^{\mathrm{0}} 9.985$, publicada em 18 de julho de 2000, que institucionaliza as Unidades de Conservação (SNUC), traz duas definições a seguir:

XI - Uso sustentável: exploração do ambiente de maneira a garantir a perenidade dos recursos ambientais renováveis e dos processos ecológicos, mantendo a biodiversidade e os demais atributos ecológicos, de forma socialmente justa e economicamente viável;

XII - Extrativismo: sistema de exploração baseado na coleta e extração, de modo sustentável, de recursos naturais renováveis;

Assim, depreende-se que a principal atividade econômica em uma RESEX deva ser o extrativismo, exercido de forma sustentável, garantindo a perenidade e continuidade dos processos ambientais e ecológicos. Espera-se, portanto, que tais atributos sejam encontrados junto aos atores que atuam diretamente em RESEX, os quais podem ser contrastados a partir do Quadro 1, onde os DCSs podem ser observados. 
Quadro 1. Discurso do Sujeito Coletivo sobre o entendimento de "extrativismo"

\begin{tabular}{|l|l|}
\hline Extrativistas & $\begin{array}{l}\text { O extrativismo é bom, um importante meio de sobrevivência; um modo de } \\
\text { vida. Porém, falta incentivo das autoridades com estrutura para produção, } \\
\text { beneficiamento e armazenamento dos produtos. É, ainda, extrair o } \\
\text { produto da floresta, e para alguns de nós, é importante não danificá-la. } \\
\text { Ainda, assim, temos uma pequena parte que se utiliza da agricultura para } \\
\text { melhorar a renda. }\end{array}$ \\
\hline $\begin{array}{l}\text { Organizações não } \\
\text { governamentais }\end{array}$ & $\begin{array}{l}\text { Extrativismo é uma atividade que permite viver da floresta, retirando-se os } \\
\text { produtos sem degradar a natureza, porém que precisa de investimento do } \\
\text { Estado. }\end{array}$ \\
\hline $\begin{array}{l}\text { Organizações } \\
\text { públicas }\end{array}$ & $\begin{array}{l}\text { Extrativismo é a utilização sustentável e racional dos recursos naturais, } \\
\text { explorando a natureza sem degradar, e tirando dela o sustento. É viver do } \\
\text { que a floresta oferece; uma fonte de renda para os extrativistas. }\end{array}$ \\
\hline
\end{tabular}

Fonte: Dados de pesquisa.

De forma geral, os extrativistas vinculam a sua atividade à questão da sobrevivência, dando uma conotação na qual ser extrativista significa lutar para se manter vivo. Certamente, é reconhecido em alguns trabalhos (VALIANTE, 2008; MOREIRA, 2010; TEIXEIRA, 2010) que a renda do extrativista é, via de regra, bastante reduzida, motivo pela qual essa afirmação aparece de forma clara. Em menor escala, apareceu o conceito de "não danificar" como aquilo que mais se aproximaria de um conceito sustentável, apontada pelos extrativistas.

Outra situação de destaque é o excessivo número de extrativistas que não responderam e não sabem, ou outros cujas respostas estiveram tão distantes da definição de extrativismo, que não puderam ser categorizadas. Isto demonstra, $a$ priori, que os moradores dessas Unidades de Conservação não compreendem o que o extrativismo representa em uma perspectiva mais ampla, ou seja, não sabem o porquê eles vivem nessas áreas, o que certamente está relacionado a um baixo grau de institucionalização do conceito central que criou as Reservas Extrativistas.

No tocante às organizações não governamentais, compostas pelas associações e entes de apoio privados que gravitam em torno dessas áreas, seu DSC apresenta preocupação com "viver" com a "degradação ambiental", sendo possível verificar um discurso mais sofisticado quando comparado com os extrativistas, aproximando-se mais da concepção original de RESEX. 
As organizações públicas apresentam um DSC, que contempla os pontos principais da atividade "extrativismo", conceituando-o de forma sustentável e racional e ainda aliado à renda do extrativista. Os discursos estão em conformidade com o exposto na Lei do SNUC, trata-se do "discurso politicamente correto" destas organizações.

Certamente, os discursos das organizações são bastante distintos dos extrativistas. Em termos comparativos, demonstra-se que aquilo que está institucionalizado nas organizações, principalmente públicas, diverge daquilo que os extrativistas compreendem de sua própria atividade, e indica que embora se conheça o conceito da função sustentável da atividade extrativista, as organizações, no mínimo, pouco fazem para que essa informação chegue aos primeiros atores. É onde o DSC dos extrativistas se aproxima das organizações não governamentais, uma vez que está explícita a necessidade de investimento do Estado.

Outro contraste em relação à concepção de RESEX pode ser verificado na análise do "desenvolvimento" sob a perspectiva destes atores, conforme consta no Quadro 2. No discurso do sujeito coletivo de todos os atores, percebe-se a predominância do entendimento de desenvolvimento em sua conotação econômica, pois remete-se à estrutura e infraestrutura no interior das RESEX.

Quadro 2. Discurso do Sujeito Coletivo sobre o entendimento de "desenvolvimento"

\begin{tabular}{|l|l|}
\hline Extrativistas & $\begin{array}{l}\text { Para nós desenvolvimento é asfalto, transporte, educação, saúde, } \\
\text { luz. É também melhora nas condiçóes de vida e saída do produto } \\
\text { de dentro da RESEX com garantia de venda diretamente para o } \\
\text { consumidor final. }\end{array}$ \\
\hline $\begin{array}{l}\text { Organizações } \\
\text { governamentais }\end{array}$ não & $\begin{array}{l}\text { Desenvolvimento é melhoria nas condições de vida para toda a } \\
\text { comunidade, obtendo água tratada, saneamento básico, energia, } \\
\text { saúde, educação e transporte. }\end{array}$ \\
\hline Organizações públicas & $\begin{array}{l}\text { Desenvolvimento é melhora na saúde, educação, transporte, estradas, } \\
\text { energia elétrica, para melhoria na qualidade de vida. }\end{array}$ \\
\hline
\end{tabular}

Fonte: Dados de pesquisa. 
Pelo discurso apresentado pelos extrativistas, é possível identificar que pouco deste refere-se a questões de desenvolvimento sustentável, estando diretamente relacionado a investimentos de infraestrutura, beneficiamento de produtos florestais, e investimentos na área social, tais como educação e saúde.

Esse posicionamento relaciona-se a alguns extrativistas cujas Reservas estão próximas às cidades. Estes atores sociais veem as Reservas como oportunidade, por meio do uso da área loteada, como se a RESEX fosse apenas o direito privado de uso da terra. Isto se distancia significativamente daquilo que foi institucionalizado e preconizado em lei. Os costumes urbanos adquiridos pelos extrativistas demonstram forte descaracterização de suas atividades com a finalidade primeira da criação das Reservas Extrativistas. Decorre disso, que as regras informais emanadas pelos extrativistas estão claramente em desacordo com aquilo que foi concebido na lei de criação dessas Unidades de Conservação.

Por outro lado, a visão das organizações, tanto não governamentais quanto públicas, acrescenta a definição de desenvolvimento à questão social. No entanto, atrelado à infraestrutura como determinante da melhoria de vida do extrativista, com total ausência do termo "sustentabilidade" em seus discursos. Talvez esse discurso pode ser explicado pela crença de que Unidades de Conservação, por si, restringem atividades econômicas em RESEX, sendo sustentável apenas pelo fato de ter sido criada. Conforme diz a lei, a atividade econômica deve ser de "[...] subsistência baseia-se no extrativismo e, complementarmente, na agricultura de subsistência e na criação de animais de pequeno porte [...]" (Lei n ${ }^{0} 9.985$, de 18 de julho de 2000).

É importante salientar que pelo menos uma organização pública - SEDAM - tem autorizado atividades madeireiras nas RESEX de jurisdição do Estado, e pode explicar o porquê a conservação do meio ambiente não é indicada como um fator a ser levado em consideração no discurso, bem como as associações que se beneficiam financeiramente da extração madeireira, alavancando suas atividades.

Conforme já foi verificado em Fachinello e Siena (2009), fica claro que organizações públicas de apoio têm institucionalizado formas alternativas de renda para os extrativistas, destoando da concepção original da criação das Reservas Extrativistas. O resultado negativo desse descompasso entre a proposta original de RESEX como área sustentável, bem como da liberação das atividades madeireiras nestas 
UCs estaduais, é a inibição de possibilidades inovadoras, como o tecido da floresta, que deixam de ser vistas como viáveis (MOREIRA; MULLER, 2011).

Verifica-se, na sequência, que o entendimento apresentado sobre desenvolvimento está em desacordo com a sustentabilidade ambiental, como pode ser observado a seguir (Quadro 3), na qual novamente aparecem a preservação e equilíbrio, demonstrando dificuldade de compreender desenvolvimento de forma sustentável.

Quadro 3. Discurso do Sujeito Coletivo sobre o entendimento de "sustentabilidade"

\begin{tabular}{|l|l|}
\hline Extrativistas & $\begin{array}{l}\text { Sustentabilidade é extrair o produto preservando a floresta, trabalhar } \\
\text { e sustentar a família com o extrativismo. }\end{array}$ \\
\hline $\begin{array}{l}\text { Organizações não } \\
\text { governamentais }\end{array}$ & $\begin{array}{l}\text { Sustentabilidade é manter o sustento da família com o que a floresta } \\
\text { oferece, mantendo o equilíbrio entre a natureza e o ser humano. }\end{array}$ \\
\hline Organizações públicas & $\begin{array}{l}\text { Sustentabilidade é a utilização racional dos recursos naturais, com } \\
\text { harmonia com o meio ambiente, extraindo da natureza sem prejudicá- } \\
\text { la, e garantindo o sustento da família. }\end{array}$ \\
\hline
\end{tabular}

Fonte: Dados de pesquisa.

A exemplo das respostas anteriores, percebe-se que todos os sujeitos coletivos colocam sustento em primeiro lugar, considerando floresta como seu meio de vida. No entanto, alguns extrativistas quando deparados com o conceito demonstraram em seus discursos possuir entendimento da necessidade de conservação da natureza, mesmo que seja apenas como garantia do seu sustento.

Entretanto, um número expressivo de extrativistas teve dificuldade de se posicionar, deixando claro que o conceito de sustentabilidade não se encontra totalmente institucionalizado. O que leva a entendimentos de que a linha de comunicação entre as organizações que giram em torno das reservas não está sendo eficaz em transmitir o conceito construído. É importante salientar que boa parte dos extrativistas afirmou sequer saber o que seria sustentabilidade, nunca ouviram falar e, portanto, que não imaginam do que se trata tal definição, demonstrando claramente uma dissociação com a proposta de RESEX, pelo menos em parte.

Por sua vez, o DSC das organizações não governamentais corrobora com o DSC dos extrativistas. Isto provavelmente se dá pela presença de extrativistas nas organizações pesquisadas. 
No tocante às organizações públicas, demonstra-se o conhecimento de uma visão multifacetada de sustentabilidade, congregando em um só conceito a questão ambiental, social e econômica. Entretanto, é o que se espera destas organizações, visto que é sua função zelar pela implementação de comportamentos sustentáveis. Conforme consta no texto da lei, "A Reserva Extrativista [...] tem como objetivos básicos proteger os meios de vida e a cultura dessas populações (extrativistas), e assegurar o uso sustentável dos recursos naturais da unidade" (Lei $n^{0} 9.985$, de 18 de julho de 2000). Ou seja, produção sustentável é uma premissa básica, e que deve figurar no entendimento de ambos os atores, extrativistas e organizações. Entretanto, o descolamento das informações dos extrativistas, das organizações não governamentais em relação às organizações públicas indica que a aproximação que deveria acontecer, no momento não está ocorrendo, o que evidencia haver apenas discursos.

\section{CONCLUSÕES}

Constata-se neste trabalho a presença de uma visão do paternalismo governamental por parte dos extrativistas, que acreditam na necessidade de incentivo do poder público como forma de alavancar sua produção e venda, e como consequência, resultaria na melhoria em suas condições de vida. Seu foco principal é a sobrevivência, sendo esta a principal função da floresta, que deve permanecer em pé para este fim. Entretanto, há uma clara dificuldade em expressar o conceito de sustentabilidade, ficando, por vezes, agregado à auto-sustentação.

Com relação aos atores que representam organizações públicas, se percebem respostas "prontas" e "automáticas", como um discurso previamente decorado, ressaltando que extrativismo deve ser realizado de forma sustentável, que desenvolvimento possui as dimensões econômica e social, com infraestrutura básica e de produção e, por fim, sustentabilidade dentro do paradigma ambiental, social e econômico.

Já em relação às organizações não governamentais, percebe-se uma posição intermediária, ora aproximando-se dos extrativistas ora das organizações públicas, 
entretanto, com razoável entendimento dos conceitos e parcialmente alinhadas à concepção original de RESEX.

Constata divergência de opiniões dentre os grupos de atores que giram em torno das RESEX em Rondônia, ressaltando desconhecimento ou mesmo conhecimento limitado da concepção inicial de sua criação, tal como formulada pelos próprios extrativistas na década de 1970. Tal condição pode ser resultante de ineficiência na gestão das UCs, como também de interesses dos grupos a elas relacionados, que destoam do que se concebeu. Por fim, se coloca a necessidade de estudos mais aprofundados sobre a questão de forma a identificar as razões e possíveis formas de mitigar os problemas constatados, os quais devem dar vazão aos anseios de melhoria da população produtora, bem como garantindo a conservação e preservação da floresta amazônica.

\section{REFERÊNCIAS}

ALLEGRETTI, H. Ambientalismo político y reforma agrária: de Chico Mendes al movimiento de los sien tierra. Nueva Sociedad, n. 150, p. 57-68, jul./ago. 1997.

ALLEGRETTI, M. A construção social de políticas públicas. Chico Mendes e o movimento dos seringueiros. Desenvolvimento e Meio Ambiente, n. 18, p. 39-59, jul./ dez. 2008.

ALLEGRETTI, M. H. A construção social de políticas ambientais. 2002. Tese (doutorado) - Universidade de Brasília, Brasília, Distrito Federal.

BECKER, B. K. Revisão das políticas de ocupação da Amazônia: é possível identificar modelos para projetar cenários? Parcerias Estratégicas, n. 12, p. 135-159, set. 2001.

BERGER, P. L.; LUCKMANN, T. A construção social da realidade. 33. ed. Petrópolis: Vozes, 2011.

BRASIL. Lei $\mathbf{n}^{\mathbf{0}}$ 9.985, de 18 de julho de 2000. Regulamenta o art. 225, § 1o, incisos I, II, III e VII da Constituição Federal, institui o Sistema Nacional de Unidades de Conservação da Natureza e dá outras providências. Diário Oficial da União, 19 de julho de 2000. 
CAVALCANTI, F. C. S. A política ambiental na Amazônia: um estudo sobre as reservas extrativistas. 2002. Tese (doutorado) - Universidade Estadual de Campinas, Campinas, SP.

CONCEIÇÃO, O. A. C. O conceito de instituição nas modernas abordagens institucionalistas. R. Econ. contemp., Rio de Janeiro, v. 6, n. 2, p. 119-146, jul./dez. 2002.

DIMAGGIO, P. J.; POWELL, W. The iron cage revisited: institutional isomorphism and collective rationality in organizational fields. American Sociological Review, v. 48, n. 2, p. 147-160, apr. 1983.

DIMMAGGIO, P. J. Interest and agency in institutional theory. In: ZUCKER, L. (Ed.), Institutional patterns and organizations. Cambridge, MA: Ballinger Publishing Company, 1988. p. 3-22.

EMBRAPA. Empresa Brasileira de Pesquisa Agropecuária. Centro Nacional de Monitoramento por Satélite. Disponível em: < http://www.machadinho.cnpm.embrapa.br/conteudo/polono.html> . Acesso em: 13 fev. 2012.

FACHINELLO, D. T.; SIENA, O. Problemas de gestão das reservas extrativistas de Rondônia (BR): a visão dos gestores. In: ENCONTRO DA SOCIEDADE BRASILEIRA DE ECONOMIA ECOLÓGICA, 8., 2009, Cuiabá. Anais... [s.l.; s.n.], agosto 2009.

FLIGSTEIN, N. Habilidade social e a teoria dos campos. RAE, v. 47, n. 2, abr.jun. 2007.

FORTIN, M. F. Fundamentos e etapas do processo de investigação. Loures: Lusodidacta, 2009.

GRANOVETTER, M. Economic action and social struture: The problem of embeddedness. The American Journal of Sociology, v. 91, n. 3, p. 481-510, 1985.

HOMMA, A. K. O. Extrativismo, biodiversidade e biopirataria na Amazônia. Embrapa Inf. Tecnológica, Brasília. 2008. (Texto para discussão).

LEFEVRE, A. M. C.; CRESTANA, M. F.; CORNETTA, V. K. A utilização da metodologia do discurso do sujeito coletivo na avaliação qualitativa dos cursos de especialização 
"Capacitação e Desenvolvimento de Recursos Humanos em Saúde-CADRHU", São Paulo - 2002. Saúde e Sociedade, v. 12, n. 2, p. 68-75, jul./dez. 2003.

LEFEVRE, F.; LEFEVRE, A. M. C. O sujeito coletivo que fala. Interface - Comunicação, Saúde, Educação, v. 10, n. 20, p. 517-524, jul./dez. 2006.

MACHADO-DA-SILVA, C. L.; GUARIDO FILHO, E. R.; ROSSONI, L. Campos Organizacionais: Seis Diferentes Leituras e a Perspectiva de Estruturação. Revista de Administração Contemporânea, n. Edição Especial, p. 109-147, 2010.

MACIEL, R. C. G. Ilhas de alta produtividade: inovação essencial para a manutenção dos seringueiros nas reservas extrativistas. 2003. Dissertação (Mestrado) - Universidade Estadual de Campinas, Instituto de Economia, Campinas, 2003.

MEYER, J. W.; ROWAN, B. Institutionalized Organization: formal struture as myth and ceremony. The American Journal of Sociolog y, v. 82, n. 2, p. 340-363, 1977.

MOREIRA, R. C. S. A produção extrativa e o manejo florestal em reservas extrativistas: o caso da RESEX Aquariquara de Rondônia. 2010. Dissertação (Mestrado) - Fundação Universidade Federal de Rondônia, Porto Velho, RO.

MOREIRA, R. C. S.; MULLER, C. A. D. S. A produção extrativista e o manejo florestal na reserva extrativista Aquariquara no Estado de Ronônia. RARA - Revista de Administração e Negócios da Amazônia, Porto Velho, v. 3, n. 2, p. 1-13, maio/ago. 2011.

MOURÃO, P. R. O Institucionalismo Americano: raízes e presente. Enciclopédia Virtual, 2007. Disponível em: <http://www.eumed.net/eve/resum/06-04/prm.htm>.

POWELL, W. W.; DIMAGGIO, P. J. The new institutionalism in organizational analysis. London: The University of Chicago Press, 1991.

SIENA, O. et al. Sustentabilidade dos produtos florestais não-madeiráveis (PFNM) do estado de Rondônia. RARA - Revista de Administração e Negócios da Amazônia, Porto Velho, v. 2, n. 1, 2011.

SIENA, O.; FACHINELLO, D. T.; MAIA, D. D. S. Constatações sobre reservas extra- 
tivistas no Estado de Rondônia. In: ENCONTRO NACIONAL DA ANPPAS, 5., 2010, Florianópolis, SC. Anais... Florianópolis: ANPPAS, 2010.

SWEDBERG, R. Sociologia econômica: hoje e amanhã. Tempo Social, Revista de Sociologia da USP, v. 16, n. 2, 2004.

TEIXEIRA, O. T. S. Sustentabilidade econômica da produção extrativa não madeirável (pfnm) na reserva do lago de Cuniã (RO). Dissertação (mestrado) - Fundação Universidade Federal de Rondônia, Porto Velho, RO.

TOLBERT, P. S.; ZUCKER, L. A institucionalização da teoria institucional. In: CLEGG, S. R. et al. Handbook de estudos organizacionais. São Paulo: Atlas, 2010. Cap. 6, p. 194-225.

UNIR. Universidade Federal de Rondônia (UNIR). Núcleo de Ciências Sociais Aplicadas. Mestrado em Administração. Relatório de Pesquisa Busca da Sustentabilidade para os Produtos Não-Madeiráveis (PFNM) para o Estado de Rondônia. Porto Velho: Edital 16/2008 (Casadinho). 2011.

VALIANTE, J. O. A sustentabilidade da produção extrativa da RESEX do Rio Ouro Preto (RO). 2008. Dissertação (mestrado) - Fundação Universidade Federal de Rondônia, Porto Velho, RO.

Recebido em: 18 de maio de 2015 Aceito em: 23 de janeiro de 2016 